\title{
Diabetic nephropathy in type 1 diabetes: has the outlook improved since the 1980s?
}

\author{
S. M. Marshall
}

Received: 26 March 2012 / Accepted: 23 May 2012 / Published online: 14 June 2012

(C) Springer-Verlag 2012

\begin{abstract}
This edition of Then and Now discusses three papers published in Diabetologia in the 1980s relating to diabetic nephropathy. Two epidemiological papers by Andersen et al (1983; 25:496-501) and Borch-Johnsen et al $(1985 ; 28: 590-596)$ described in graphic detail the ravages of diabetic nephropathy in type 1 diabetes. After 40 years of diabetes, $41 \%$ of their cohort had developed persistent proteinuria. The median time from first appearance of proteinuria to death was 7-8 years, the majority dying of uraemia or cardiovascular disease. The third paper, by Mathiesen et al (1984; 26:406-410), identified individuals with microalbuminuria, a much earlier stage of diabetic nephropathy, and analysed the risk of progression to persistent proteinuria at various levels of urine albumin excretion. Since the description of microalbuminuria, clinicians have hoped that earlier identification of individuals at high risk of end-stage kidney disease, coupled with aggressive use of reno-protective therapies, would prevent, or at the very least significantly delay, the development of end-stage renal disease. Recent data suggest that the outlook has indeed improved since the $1980 \mathrm{~s}$, at least in some populations. However, we may be delaying rather than preventing the development of microalbuminuria, proteinuria and kidney failure. Whilst a delay of 10 or more years in the appearance of end-stage renal disease is very welcome, further work is needed to understand why rates of chronic kidney disease vary substantially between cohorts and to develop novel therapies.
\end{abstract}

\footnotetext{
S. M. Marshall ( $\square)$

Faculty of Clinical Medical Sciences, Institute of Cellular

Medicine, Newcastle University,

Floor 4, Leech Building, Framlington Place,

Newcastle upon Tyne NE2 4HH UK

e-mail: sally.marshall@newcastle.ac.uk
}

Keywords Diabetic nephropathy · End-stage renal disease Microalbuminuria $\cdot$ Persistent proteinuria $\cdot$ Type 1 diabetes
Abbreviations
CVD Cardiovascular disease
eGFR Estimated GFR
ESRD End-stage renal disease
SMR Standardised mortality rate
UAE Urine albumin excretion

\section{Introduction}

At the beginning of the 1980 s, diabetic nephropathy was diagnosed late, at the appearance of dipstick-positive proteinuria, when kidney damage was severe and irreversible. Preliminary data derived from small studies in selected populations suggested that the outlook was grim. Two of the three studies in this edition of Then and Now are large epidemiological studies which highlight this poor prognosis $[1,2]$. The third study [3], along with others published immediately beforehand [4-6], brought hope for an earlier diagnosis at a time when end-stage disease might be preventable. These studies have all been quoted extensively, and laid the foundation for much further research and, indeed, change in clinical practice. Has this resulted in an improved outlook for the person with type 1 diabetes?

\section{Then}

Proteinuria, mortality and end-stage renal disease The study by Andersen et al [1] included a cohort of 1,475 individuals with 'type 1 diabetes': onset of diabetes at age 
$<31$ years, diagnosed before 1953 , and who were referred to the Steno Memorial Hospital between 1932 and 1977. The median duration of diabetes at referral was 7 years and $73 \%$ were referred at $<16$ years' duration. The main reason for referral was difficulty with glucose control, rather than the presence of complications. Individuals were followed until a diabetes duration of at least 25 years or to death.

During follow-up, $41 \%$ developed persistent proteinuria because of diabetic nephropathy, defined as total protein excretion $>0.5 \mathrm{~g} / 24 \mathrm{~h}$ or Albustix-positive proteinuria in four or more consecutive samples. A further $3 \%$ had persistent proteinuria which was due to another cause and $57 \%$ remained free of proteinuria. The maximum prevalence of proteinuria was $21 \%$ at $20-25$ years' duration of diabetes, and $\sim 10 \%$ at $\geq 40$ years. Only $4 \%$ developed proteinuria within 10 years' duration of diabetes. There were two peaks in the annual incidence, the larger at 16 years' duration (3\%) and a smaller second peak at 32 years' duration (2\%). For a duration of diabetes of $\geq 40$ years, the annual incidence was $\sim 1 \%$. Those with a very long diabetes duration seemed to be at low risk, with only $4 \%$ developing proteinuria after more than 35 years duration. Thus, the cumulative incidence of proteinuria appeared to plateau after 35-40 years of diabetes, suggesting that only a subset of individuals will ever develop nephropathy.

The poor prognosis was illustrated starkly: $83 \%$ of those who developed persistent proteinuria died during follow-up compared with $25 \%$ of those without proteinuria. Uraemia accounted for $66 \%$ of deaths, and ischaemic heart disease and stroke for $19 \%$. Within 7 years of the onset of persistent proteinuria, $49 \%$ had died.

The paper by Borch-Johnsen et al [2] included a cohort of patients similar, but not identical, to those in the Andersen et al paper, as individuals diagnosed before 1933 were excluded. Follow-up was until January 1982, death or emigration. Of the 1,001 individuals with full information, 406 had persistent proteinuria at referral or developed it during follow-up. The incidence of proteinuria rose dramatically after 10 years of diabetes, reaching a maximum after 13-18 years of diabetes, after which it decreased. No second peak was observed. The incidence of persistent proteinuria decreased with increasing year of diagnosis from 1933 to 1952 . Of those with proteinuria, 350 died. The relative risk of death of those with proteinuria, compared with the background Danish population, increased sharply from age 20 years, reaching almost 100 at age 30-40 years (median duration of diabetes $15-25$ years), before declining sharply again. In those without proteinuria, relative mortality was about 2 and remained relatively constant throughout life. Life expectancy was 50\% longer in those diagnosed in 1950 compared with those diagnosed in 1935 , mainly as a result of the decreasing incidence of persistent proteinuria. Individuals who developed proteinuria after a diabetes duration of 15 years had a better prognosis than those who developed it earlier. Uraemia accounted for $66 \%$ of deaths in those with proteinuria, and cardiovascular disease (CVD) was the cause of $23 \%$. Mortality from CVD was almost tenfold higher in those with proteinuria compared with those without.

Thus, these two papers demonstrated that a subset of approximately $40 \%$ of individuals with type 1 diabetes developed persistent proteinuria, with its associated enormous increase in relative mortality and a median survival time of $7-8$ years.

Microalbuminuria The generally accepted clinical definition of diabetic nephropathy is persistent urine protein excretion $>0.5 \mathrm{~g}$ per $24 \mathrm{~h}$, or the presence of dipstick-positive proteinuria. However, normal urine protein excretion is at least tenfold lower. Thus, persistent proteinuria represents relatively advanced urine protein leak. The development of a sensitive radioimmunoassay, specific for albumin, the main urine protein excreted early in diabetic nephropathy, allowed the measurement of urine albumin concentrations in the normal range [7]. This was quickly followed by the demonstration that, in some newly diagnosed individuals with type 2 diabetes, urine albumin excretion (UAE) was higher than in non-diabetic individuals [8]. This observation appears to have been ignored largely until the early 1980s, when three groups demonstrated that type 1 diabetic individuals with a UAE rate greater than normal but without dipstick-positive proteinuria were much more likely to develop persistent proteinuria or to die than their peers with a UAE rate within the normal range [4-6]. Albuminuria in this range was named microalbuminuria and heralded a new era in diabetes research.

The paper by Mathiesen et al [3] quickly followed from these original descriptions of the significance of microalbuminuria. In a longitudinal cohort, UAE had been measured in 71 consecutive, dipstick-negative type 1 diabetic patients in 1974. Sixteen had a UAE rate $>20 \mu \mathrm{g} / \mathrm{min}$ initially, the upper limit of the normal range (mean $+2 \mathrm{SD}$ ), determined in 19 non-diabetic individuals. Five of the 71 developed a UAE rate $>200 \mu \mathrm{g} / \mathrm{min}$ and an additional five developed persistent proteinuria during a 6-year follow-up. Those individuals who progressed had a higher baseline UAE and systolic blood pressure and were more likely to have retinopathy at baseline than those who remained normoalbuminuric. All seven individuals who had a baseline UAE rate $>70 \mu \mathrm{g} / \mathrm{min}$ progressed, while only three of 64 individuals with an initial UAE rate $\leq 70 \mu \mathrm{g} / \mathrm{min}$ did so. Those with a UAE rate $>70 \mu \mathrm{g} / \mathrm{min}$ initially had a much greater rise in blood pressure and serum creatinine during the 6-year follow-up than those with lesser degrees of albuminuria or normal albumin excretion.

Mathiesen et al also studied a cross-sectional cohort of 227 randomly selected dipstick-negative type 1 diabetic individuals. Of these, $67 \mathrm{had}$ a UAE rate $>20 \mu \mathrm{g} / \mathrm{min}$. 
Systolic and diastolic blood pressure were higher in these individuals compared with those with lower levels of albuminuria and normal albumin excretion. They were also more likely to have proliferative retinopathy. GFR was similar; all demonstrated hyperfiltration. Glycaemic control $\left(\mathrm{HbA}_{1 \mathrm{c}}\right.$ and urine glucose) differed little across UAE groups.

\section{Now}

Change in incidence of proteinuria — delay or prevention? The papers by Andersen et al [1] and Borch-Johnsen et al [2] set the yardstick against which our progress in the prevention of nephropathy in type 1 diabetes is judged. Has the incidence declined? Are we preventing nephropathy? The dearth of population-based or large cohort studies reporting such data is testament to the difficulty of performing such epidemiological work. However, relevant studies are summarised in Table 1 [9-14]. There is a striking variation between cohorts. However, in the majority, the cumulative incidences of persistent proteinuria and of ESRD for a duration of diabetes of 25-30 years have declined since the paper by Andersen et al was published. Several studies also suggest that the cumulative incidence of proteinuria is declining with increasing year of calendar diagnosis of diabetes [10, 13]. Aggregated data from the European Dialysis and Transplant Association Registry from 1990 onwards show an unchanged reported rate of ESRD in type 1 diabetes, at a time when the prevalence of type 1 diabetes is increasing, and survival is also improving [15]. In contrast to the large peak in annual incidence of proteinuria at a diabetes duration of about 16 years reported by Andersen et al [1], more recent studies have shown a lower, relatively constant annual incidence for durations between 19 and 30 years [10, 14]. However, when the annual incidence is summated into cumulative incidence and extended to include durations of diabetes $>30$ years, the cumulative incidence of nephropathy in the more recent studies appears to at least equal that of the older studies, but with a 5-15 year delay in the appearance of proteinuria (Fig. 1). Thus, rather than prevention, we may only be delaying the onset of proteinuria. It is likely that many factors have contributed to this delay, including improved glycaemic and blood pressure control, increased use of statins and inhibitors of the renin-angiotensin system and a reduction in smoking.

Change in incidence of end-stage renal disease? Recent observations from Finland [13] and Sweden [14] report rates of ESRD in individuals with persistent proteinuria of 2.5-7.8\% at 30 years duration of type 1 diabetes, whilst in the DCCT/ EDIC cohort the reported rates after 25 years duration were $2 \%$ and $1 \%$ in the conventionally and intensively managed groups, respectively [9]. In 22 years of follow-up of the DCCT/EDIC cohort, only 24 participants assigned to intensive therapy and 46 to conventional therapy developed an estimated GFR (eGFR) $<60 \mathrm{ml} \mathrm{min}{ }^{-1} 1.73 \mathrm{~m}^{-2}$ (risk reduction $p=0.006$ ) [16]. Thus, the incidence of ESRD in type 1 diabetes does appear to be lower than that reported in the 1980s, although again the difference between centres is substantial.

Change in survival and cause of death in proteinuric type 1 diabetic individuals? The paper by Borch-Johnsen et al [2] demonstrated the dismal survival of type 1 diabetic patients with proteinuria compared with those without proteinuria and with the general population, the median survival time following the appearance of proteinuria being 7-8 years. Has this changed? One paper suggests that the median survival time from the onset of proteinuria has improved over the years to 21.7 years [17]. In this recent cohort, $42 \%$ of the deaths were attributed to CVD, and $50 \%$ died with ESRD. However, CVD mortality and ESRD are competing risks, and sophisticated analyses are required to control for this. Two recent papers performed such analyses and estimated that the current incidence of ESRD in type 1 diabetic

Table 1 Cumulative prevalence of diabetic nephropathy or end stage renal disease after 20-40 years of type 1 diabetes

\begin{tabular}{|c|c|c|c|c|c|}
\hline \multirow[t]{2}{*}{ Study [ref.] } & \multirow[t]{2}{*}{ Country } & \multirow{2}{*}{$\begin{array}{l}\text { Year of diagnosis } \\
\text { of diabetes }\end{array}$} & \multirow{2}{*}{$\begin{array}{l}\text { Duration of } \\
\text { diabetes (years) }\end{array}$} & \multicolumn{2}{|c|}{ Cumulative incidence $(\%)$} \\
\hline & & & & Proteinuria & ESRD \\
\hline Andersen [1] & Denmark & Before 1953 & 40 & 41 & \\
\hline DCCT/EDIC [9] & USA & $\sim 1978-1988$ & 30 & $\begin{array}{l}\text { Conventional: } 25 \\
\text { Intensive: } 9\end{array}$ & $\begin{array}{l}\text { Conventional: } 2 \mathrm{~s} \\
\text { Intensive: } 1\end{array}$ \\
\hline Pambianco [10] & USA & $1965-1980$ & 25 & 32 & \\
\hline Hovind [11] & Denmark & 1979-1984 & 20 & 13.7 & \\
\hline Nordwall [12] & Sweden & $1971-1975$ & 25 & 13 & \\
\hline Finne [13] & Finland & 1965-1999 & 30 & & 7.8 \\
\hline Mollsten [14] & Sweden & 1977 onwards & 30 & & $\begin{array}{l}4.1 \text { (men) } \\
2.5 \text { (women) }\end{array}$ \\
\hline
\end{tabular}




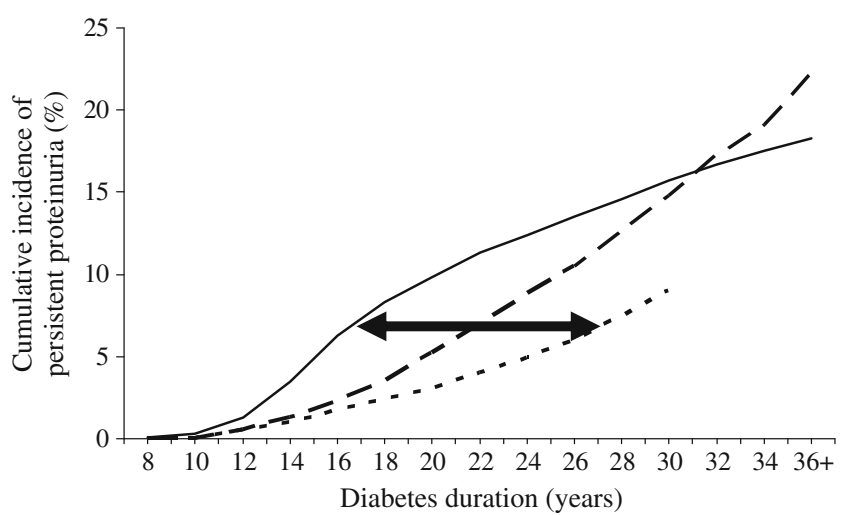

Fig. 1 Changing cumulative incidence of persistent proteinuria in type 1 diabetes by duration of diabetes $[1,9,10]$. The horizontal arrow represents the potential delay in appearance of persistent proteinuria. Solid line, Steno cohort, diagnosed before 1953 [1]; long dashed line, Pittsburgh cohort, diagnosed 1950-1980 [10]; short dashed line, intensively managed DCCT cohort, diagnosed 1978-1988

individuals with persistent proteinuria is $5.1-5.8$ per 100 person-years $[18,19]$. In one of these studies, $36 \%$ developed ESRD and $9 \%$ died without ESRD over a 9.9-year follow-up [18], with different baseline factors determining the individual specific outcome. In the second study, despite an increased use of reno-protective therapies, the risk of ESRD did not change from 1993 to 2008 [19]. The 15 -year cumulative risk was $52 \%$ for ESRD and $11 \%$ for pre-ESRD death. Why these figures are poorer than those from other groups $[9,17]$ remains conjecture. However, in all series, the time from onset of proteinuria to ESRD or death is greatly improved from that reported in the early 1980s, again suggesting delay rather true prevention.

Microalbuminuria Initial studies suggested a lifetime risk of developing microalbuminuria of approximately $50 \%$, generally appearing at a type 1 diabetes duration of between 10 and 20 years. The natural history was believed to be progressive to dipstick-positive proteinuria in most individuals. It was hoped that, with intensified management of glucose, blood pressure and cardiovascular risk factors, microalbuminuria would be prevented, or at the very least progression to proteinuria and ESRD would be halted. Has this hope been fulfilled? In the DCCT/EDIC cohort, the cumulative incidence of persistent microalbuminuria was $38 \%$ after 30 years in the conventional group and $25 \%$ in the intensive group [20]. The incidence appears to plateau in both groups after 25-30 years. Microalbuminuria developed most frequently in the second decade of diabetes in the conventional group, the incidence being particularly blunted during this time in the intensive group. Of note, in the 10 years following the first appearance of persistent microalbuminuria, regression to normoalbuminuria occurred in $40 \%$, with $28 \%$ developing proteinuria and $4 \%$ ESRD. Use of intensive insulin therapy and lower $\mathrm{HbA}_{1 \mathrm{c}}$ levels were associated with better renal outcomes. This confirms reports from other cohorts that, even after persisting for several years, microalbuminuria may revert to normal [21]. Thus, the data suggest that microalbuminuria is being delayed or prevented, particularly by intensive glucose management, and that rates of regression from microalbuminuria to normal albumin excretion are much higher and progression rates to proteinuria lower than first believed.

Is the clinical phenotype of diabetic kidney disease changing? In the 1980s, diabetic nephropathy was envisaged as a continuously progressing process, beginning with microalbuminuria that increased gradually until urine protein excretion became detectable by standard urine dipstick (proteinuria). Proteinuria then progressed gradually towards the nephrotic range. Glomerular filtration began to decline at a relatively late stage, when dipstick-positive proteinuria was present. As described above, we are now aware that microalbuminuria may regress to normal albumin excretion. There is also some evidence that proteinuria may regress to microalbuminuria, at least temporarily, usually with intensification of blood pressure control [22].

It has also become apparent that GFR may decline progressively in individuals with normal albumin excretion or non-progressive low-level microalbuminuria [23, 24]. In the DCCT cohort, $72 \%$ of individuals who developed sustained

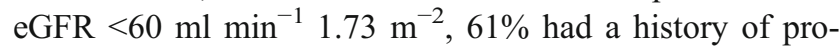
teinuria and $16 \%$ had microalbuminuria, but the other $23 \%$ persistently had normal albumin excretion [23]. In a second cohort, the proportions were $72 \%, 21 \%$ and $7 \%$, respectively [24]. Whether this phenotype represents a different form of diabetic nephropathy or another disease process remains to be determined. However, the clinical implication is that screening for kidney disease in diabetes must include measures of both urine albumin excretion and glomerular filtration.

Why is the risk of CVD increased? The demonstration of the huge premature mortality, primarily from CVD, in type 1 diabetic individuals with proteinuria was followed by studies describing the increased risk associated with microalbuminuria $[25,26]$. Two more recent studies have confirmed that the all-cause standardised mortality rates (SMR) in type 1 diabetic patients with microalbuminuria is two to three times that of the general population, 9-12 fold for those with proteinuria and 18-30 fold for those with ESRD [27, 28]. Perhaps even more important is the observation that, in those with normal albumin excretion at baseline and who remain normoalbuminuric, the SMR over 10 years [27] and 20 years [28] is similar to that of the general population.

Why CVD mortality is so high in type 1 diabetic individuals with any evidence of renal disease remains unclear. These individuals undoubtedly have an excess of classical 
CVD risk factors, and a number of novel factors have also been described. The inherited predisposition to nephropathy appears to encompass CVD risk factors and disease [29, 30]. Insulin resistance, observed in the report by Andersen et al as increased insulin dose $/ \mathrm{kg}$ body weight [1], but not recognised as such, also seems part of the familial susceptibility [31]. However, genetic testing has so far failed to identify robustly those at risk [32]. A full discussion of the links between albuminuria and CVD is beyond the scope of this article, but the topic has been reviewed recently [33].

\section{Conclusions}

The seminal papers by Andersen et al [1] and BorchJohnsen et al [2] detailed a $40 \%$ chance of an individual with type 1 diabetes developing dipstick-positive proteinuria over 40 years duration of diabetes. Median survival from first appearance of proteinuria was 7-8 years, with the majority dying of uraemia and CVD. The discovery of microalbuminuria provided us with the ability to identify those at very high risk of chronic kidney disease and CVD at a much earlier stage, and raised hopes that earlier intervention with aggressive management of glucose, blood pressure and CVD risk factors would improve the outlook. Using the Andersen et al [1] and Borch-Johnsen et al [2] data as our yard-stick, the incidence of proteinuria at a diabetes duration of 30 years has declined, but this almost certainly represents a delay in onset rather than true prevention. Kidney and patient survival once proteinuria has appeared have also improved, but remain much poorer than in the person with type 1 diabetes and normal albumin excretion. The incidence of microalbuminuria is also less than expected, but again this may be a delay in appearance rather than true prevention. One major challenge for the future is identifying reasons why rates of proteinuria and survival times differ so widely between centres. Is this due to differences in standards of care, different genetic susceptibilities or other factors? Novel therapies are also required.

Duality of interest The author declares that there is no duality of interest associated with this manuscript.

Contribution statement The author takes sole responsibility for the conception, design and drafting of the manuscript and approval of the final version for publication.

\section{References}

1. Andersen AR, Sandahl Christiansen J, Andersen LK, Kreiner S, Deckert T (1983) Diabetic nephropathy in type 1 (insulin-dependent) diabetes: an epidemiological study. Diabetologia 25:496-501
2. Borch-Johnsen K, Andersen PK, Deckert T (1985) The effect of proteinuria on relative mortality in type 1 (insulin-dependent) diabetes mellitus. Diabetologia 28:590-596

3. Mathiesen ER, Oxenboll B, Johansen K, Svendsen PA, Deckert T (1984) Incipient nephropathy in type 1 (insulin-dependent) diabetes. Diabetologia 26:406-410

4. Viberti GC, Hill RD, Jarrett RJ, Argyropoulos A, Mahmud U, Keen H (1982) Microalbuminuria as a predictor of clinical nephropathy in insulin-dependent diabetes mellitus. Lancet 1:14301432

5. Parving HH, Oxenboll B, Svendsen PA, Christiansen JS, Andersen AR (1982) Early detection of patients at risk of developing diabetic nephropathy: a longitudinal study of urine albumin excretion. Acta Endocrinol 100:550-555

6. Mogensen CE, Christensen CK (1984) Predicting diabetic nephropathy in insulin-dependent patients. N Engl J Med 311:89-93

7. Keen H, Chlouverakis C (1963) An immunoassay method for urinary albumin at low concentrations. Lancet 2:913-914

8. Keen H, Chlouverakis C (1964) Urinary albumin excretion and diabetes mellitus. Lancet 2:1155-1156

9. DCCT/EDIC Research Group (2009) Modern-day clinical course of type 1 diabetes mellitus after 30 years' duration. Arch Intern Med 169:1307-1316

10. Pambianco G, Costacou T, Ellis D, Becker DJ, Klein R, Orchard T (2006) The 30-year natural history of type 1 diabetes complications. Diabetes 55:1463-1469

11. Hovind P, Tarnow L, Rossing K et al (2003) Decreasing incidence of severe diabetic microangiopathy in type 1 diabetes. Diabetes Care 26:1258-1264

12. Nordwall M, Bojestig M, Arnqvist HJ, Ludvigsson J, Linkoping Diabetes Complications Study (2004) Declining incidence of severe retinopathy and persisting decrease of nephropathy in an unselected population of Type 1 diabetes - the Linkoping Diabetes Complications Study. Diabetologia 47:1266-1272

13. Finne P, Reunanen A, Stenman S, Groop PH, Gronhagen-Riska C (2005) Incidence of end-stage renal disease in patients with type 1 diabetes. JAMA 294:1782-1787

14. Mollsten A, Svensson M, Waernbaum I et al (2010) Cumulative risk, age at onset, and sex-specific differences for developing endstage renal disease in young patients with type 1 diabetes: a nationwide population-based cohort study. Diabetes 59:1803-1808

15. Van Dijk PC, Jager KL, Stengel B, Grönhagen-Riska C, Feest TG, Briggs DJ (2005) Renal replacement therapy for diabetic end-stage renal disease: data from 10 registries in Europe (1991-2000). Kidney Int 67:1489-1499

16. DCCT/EDIC Research Group (2011) Intensive diabetes therapy and glomerular filtration rate in type 1 diabetes. $\mathrm{N}$ Engl $\mathrm{J}$ Med 365:2366-2376

17. Astrup AS, Tarnow L, Rossing P, Pietraszek L, Riis Hansen P, Parving HH (2005) Improved prognosis in type 1 diabetic patients with nephropathy: a prospective follow-up study. Kidney Int 68:1250-1257

18. Forsblom C, Harjutsalo V, Thorn LM et al (2011) Competing risk analysis of ESRD and death among patients with type 1 diabetes and macroalbuminuria. J Am Soc Nephrol 22:537-544

19. Rosolowsky ET, Skupien J, Smiles A et al (2011) Risk for ESRD in type 1 diabetes remains high despite renoprotection. J Am Soc Nephrol 22:545-553

20. de Boer IH, Rue TC, Cleary PA et al (2011) Long-term renal outcomes of patients with type 1 diabetes mellitus and microalbuminuria: an analysis of the Diabetes Control and Complications Trial/Epidemiology of Diabetes Interventions and Complications cohort. Arch Intern Med 171:412-420

21. Perkins BA, Ficociello LH, Silva KH, Finkelstein DM, Warram JH, Krolewski AS (2003) Regression of microalbuminuria in type 1 diabetes. N Engl J Med 348:2285-2293 
22. Hovind P, Rossing P, Tarnow L, Toft H, Parving J, Parving HH (2001) Remission of nephrotic-range albuminuria in type 1 diabetic patients. Diabetes Care 24:1972-1977

23. Molitch ME, Steffes M, Sun W et al (2010) Development and progression of renal insufficiency with and without albuminuria in adults with type 1 diabetes in the Diabetes Control and Complications Trial and the Epidemiology of Diabetes Interventions and Complications Study. Diabetes Care 33:1536-1543

24. Costacou T, Ellis P, Fried L, Orchard TJ (2007) Sequence of progression of albuminuria and decreased GFR in persons with type 1 diabetes: a cohort study. Am J Kidney Dis 50:721-732

25. Deckert T, Yokoyama H, Mathiesen ER et al (1996) Cohort study of predictive value of urinary albumin excretion for atherosclerotic vascular disease in patients with insulin dependent diabetes. BMJ 312:871-874

26. Rossing P, Houggard P, Borch-Johnsen K, Parving HH (1996) Predictors of mortality in IDDM: 10 year observational followup study. BMJ 313:779-784

27. Groop PH, Thomas MC, Moran JL et al (2009) The presence and severity of chronic kidney disease predicts all-cause mortality in type 1 diabetes. Diabetes 58:1651-1658
28. Orchard TJ, Secrest AM, Miller RG, Costacou T (2010) In the absence of renal disease, 20 year mortality risk in type 1 diabetes is comparable to that of the general population: a report from Pittsburgh Epidemiology of Diabetes Complications Study. Diabetologia 53:2312-2319

29. Earle K, Walker J, Hill C, Viberti G (1992) Familial clustering of cardiovascular disease in patients with insulin-dependent diabetes and nephropathy. N Engl J Med 326:673-677

30. Thorn LM, Forsblom C, Fagerudd J, Pettersson-Fernholm K, Kilpikari R, Groop PH, on behalf of the FinnDiane Study Group (2007) Clustering of risk factors in parents of patients with type 1 diabetes and nephropathy. Diabetes Care 30:1162-1167

31. Orchard TJ, Chang YF, Ferrell RE, Petro N, Ellis DE (2002) Nephropathy in type 1 diabetes: a manifestation of insulin resistance and multiple genetic susceptibilities? Kidney Int 62:963-970

32. Thomas MC, Groop PH, Tryggvason K (2012) Towards understanding the inherited susceptibility for nephropathy in diabetes. Curr Opin Nephrol Hypertens 21:195-202

33. Stehouwer CDA, Smulders YM (2006) Microalbuminuria and risk of cardiovascular disease: analysis of potential mechanisms. J Am Soc Nephrol 17:2106-2111 